\title{
Modelling of just-in-sequence supply of manufacturing processes
}

\author{
Tamás Bányai*, and Ágota Bányai \\ University of Miskolc, Institute of Logistics, 3515 Miskolc-Egyetemváros, Hungary
}

\begin{abstract}
The customer oriented production led to the growth of complexity of manufacturing and connected logistics processes. In many production companies one of the largest asset on balance sheet is inventory. To avoid inventory problems and to be the winners of today's market situation manufacturing companies try to decrease heavy inventory levels through just-in-time based supply strategies. The aim of this research work is to analyse these supply strategies. The first part of the paper describes the just-in-time based supply and summarises the most important characteristics of them. The second part focuses on the modelling of just-in-sequence based in-plant supply. The models makes it possible to determine different in-plant supply strategies.
\end{abstract}

\section{Introduction}

Logistic processes integrate the supply chain of production companies from the purchasing of raw materials required for the final products through in-plant materials handling to the recycling/reuse of used products covering the four functional areas of logistics: purchasing, manufacturing/production, distribution, and recycling. Today the just-in-time (JIT) based material supply strategies of manufacturing processes are gaining more and more importance as, being flexible and reliable, they significantly increase the cost efficiency.

Supply strategies are part of logistic strategies. The most important tasks of logistic strategies are the followings: increase of capacity utilisation of manufacturing and logistic resources; reduction of throughput time; reduction of in-process inventory without increasing supply risk; reduction of operation costs of manufacturing and logistic processes; increase of flexibility to answer customer's demands; enhanced transparency of processes to support the efficiency of lean tools; integration of manufacturing processes into the whole enterprise process through ERP. The operation management of in-plant supply should seek to improve the cost structure of manufacturing related logistic processes, reduce transportation, warehousing and material handling costs. Probably one the most popular tool of lean and operation management is the JIT supply strategy and the newer, socalled just-in-sequence (JIS) supply strategy. According to the literature, the just-insequence supply strategy is based on JIT philosophy [1], except that the goal is not only to fulfil the $7 \mathrm{R}$ rule, but also to ensure the requested sequence of products.

* Corresponding author: alttamas@uni-miskolc.hu 


\section{Literature review}

Just-in-time became a very popular operational strategy because of its success, especially in the field of automotive industry and mechatronic assembly plants. Today just-in-time philosophy is used both in production and service industry $[2,3]$.

The development of business environment for just-in-time based supply is one of the core problems, because the roles of suppliers, customers, 3PL partners must be defined to ensure improved efficiency of related processes. The business environment can be defined as a full business cycle, where call-offs contain all information to feed production [4].

Supply models of manufacturing are mostly described as manufacturer-vendor models. One of the first works investigated the manufacturer-vendor model [5]. In a later study the importance of time was underlined and generalise the time varying demand rate $[6,7]$. Another topic that has received significant attention in the literature is the multi-level supply of manufacturing processes, where demand and manufacturing rate, delivery and material handling time are both as deterministic and stochastic parameter are taken into consideration [8].

There are three main streams of just-in-sequence literature, which are focusing on purchasing and supply chain, just-in-time production and supply strategies and optimisation of just-in-sequence supply. One of the first milestones of supply chain research was the appearance of cost-benefit models [9] and the researches in the field of selection and evaluation of suppliers [10-12]. The supply chain complexity has increased so much that their planning cannot be carried out only on the base of analytical tools of operations research, but in many cases heuristic methods and simulation techniques are required. The laws of nature may be as relevant sources of inspiration for heuristics as living bodies or human-depending phenomenon [13]. Living bodies inspired heuristics are for example ant colony optimisation [14], firefly optimisation, cuckoo search [15] or bat algorithm [16]. simulated annealing [17], gravitation search [18], intelligent water drops [19] are inspired by physical laws, while harmony search [20] is based on a strongly human-depending attitude.

Several models, can be found in the literature, defining conditions to support the decision: when is it required to change the JIT supply to JIS [21]. These researches focus on the whole supply chain and highlight the macrologistic aspects of JIS supply [22].

Production companies need to manage their supply chain efficiently, reduce cost and improve the accuracy and efficiency of delivery and in-plant supply through production strategies like JIT and JIS [21]. There is a growing interest in the field of automotive industry for JIS supply. Researches showed the following advantages of JIS supply: increased effectiveness of in-plant transportation in automotive industry [22], up-to-date automatic identification tools, like RFID wristband supports JIS processes [23], supermarket based assembly line supply can be based on JIS, especially in the case of lineintegrated supermarkets [24], JIS supply can be supported by up-to-date IT and telecommunication solutions [25].

The aim of this paper is to investigate the most important JIS supply strategies. The contribution of this paper is the description of models of JIS based manufacturing supply systems, like ship-to-sequence $(\mathrm{StS})$, build-to-sequence $(\mathrm{BtS})$ and pick-to-sequence (PtS) supply.

This paper is organized as follows. Section 2 presents a literature review, which systematically summarizes the research background of supply chain, JIT and JIS supply. Section 3 describes the model framework of JIS philosophy based in-plant and external supply. Section 4 presents the three major models of JIS supply, by the aid of which it is possible to determine the most important in-plant supply solution methods. Conclusions and future research directions are discussed in Section 5. 


\section{Model framework of just-in-sequence supply}

The advantages of JIS supply can be summarised as follows: easier application of lean tools and solutions through enhanced transparency; increased operational efficiency through high inventory turnover rate; increased level of control over manufacturing, assembly and logistics; reliable respond on customer's demands; better utilisation of resources including human resources through better supply chain management; lower costs through avoiding excess inventory (high rate of inventory turnover, decreased inventory holding costs, lower inventory damage costs). The different solutions of JIS supply can be used in different cases. Within the frame of this section authors are showing a general model framework, by the aid of which it is possible to define a wide range of JIS based supply strategies.

Figure 1 demonstrates the model framework of JIS supply. This general model makes it possible to define the different models of JIS based supply strategies. The model framework includes the following participants of the supply chain: JIS supplier, intermediate storage (traditional warehouse, consignment store or cross docking facility) manufacturing plant with production and assembly processes.

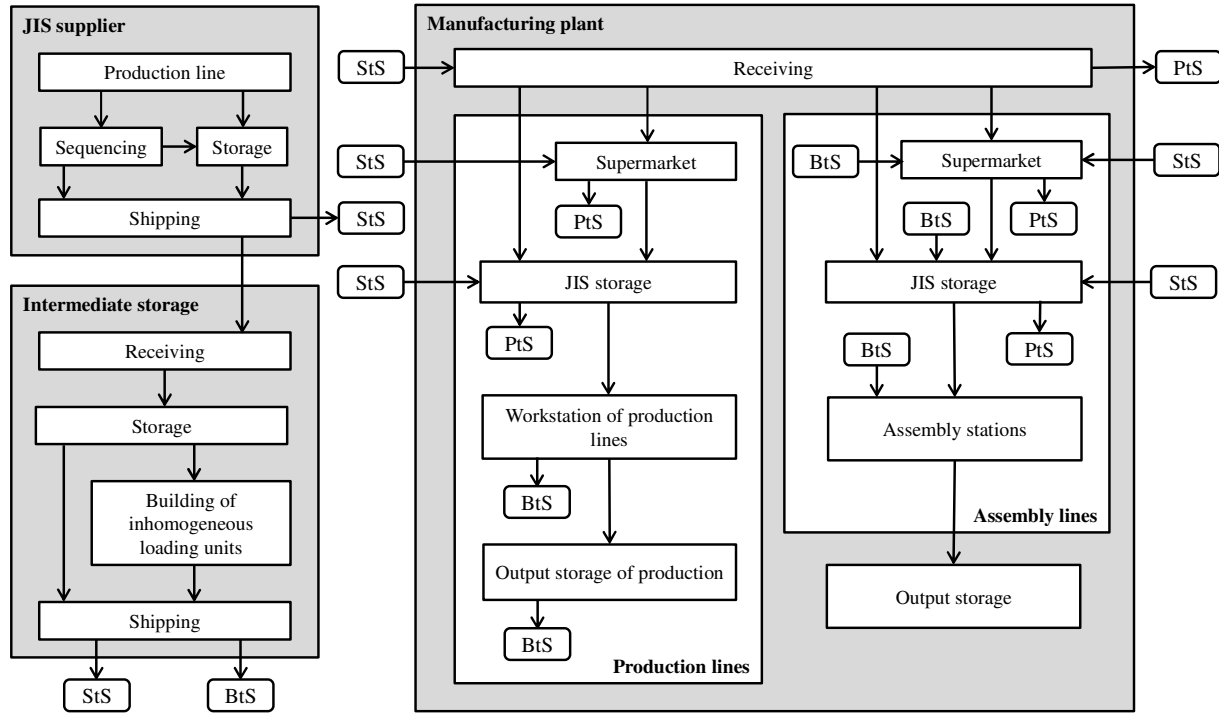

Fig. 1. Model framework of just-in-sequence supply including possible relations of pick-to-sequence, ship-to-sequence and build-to-sequence supply.

In the case of build-to-sequence, the required parts are produced according to the required sequence of the customer's assembly plant. In the case of pick-to sequence supply the required parts are sequenced and picked from a pre-production storage. It means, these solutions of supply can be defined as in-plant supply, where no external suppliers are involved. In the case of ship-to-sequence supply the supply chain represents a vertical cooperation among networking partners, like suppliers, intermediate storages and production plants as customers.

Suppliers can be involved into JIS based supply, if they have integrated IT solutions, segmented production and their purchasing is synchronised with the production processes. Intermediate storages required up-to-date identification solutions and an integrated warehouse management system to avoid failures through warehousing and related materials handling, like packaging, sequencing, building of homogeneous or inhomogeneous loading units, loading and unloading. 


\section{Modelling of just-in-sequence supply}

Within the frame of this section the major directions of just-in-sequence based supply strategies will be defined. The strategies are described with the sequence of material handling and manufacturing processes, required to supply products from JIS suppliers to customers.

\subsection{Ship-to-sequence supply}

In the case of ship-to-sequence strategy, the required products are sequenced outside of the manufacturing plant. The required products are sequenced either in the plant of JIS supplier or in the intermediate storage or cross docking facility. In this case, the inventories of the customers are decreased and shifted back to the intermediate storage of JIS supplier.

Table 1. Ship-to-sequence strategies to supply assembly plants.

\begin{tabular}{|c|c|c|c|c|c|c|c|c|c|}
\hline JIS supplier & 1 & 2 & 3 & 4 & 5 & 6 & 7 & 8 & 9 \\
\hline Outsourced production & 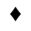 & $\bullet$ & $\bullet$ & $\bullet$ & 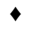 & $\bullet$ & - & $\bullet$ & $\bullet$ \\
\hline Storage & $\bullet$ & $\bullet$ & - & $\bullet$ & $\bullet$ & $\bullet$ & - & $\bullet$ & $\bullet$ \\
\hline Sequencing & $\bullet$ & $\bullet$ & $\bullet$ & $\bullet$ & $\bullet$ & $\bullet$ & & & \\
\hline Shipping to intermediate storage & & & & $\bullet$ & $\bullet$ & $\bullet$ & & & \\
\hline Shipping to customer & - & - & $\bullet$ & & & & - & - & - \\
\hline \multicolumn{10}{|l|}{ Intermediate storage } \\
\hline Receiving products from suppliers & & & & $\bullet$ & $\bullet$ & $\bullet$ & 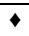 & $\bullet$ & $\bullet$ \\
\hline Storage & & & & $\bullet$ & $\bullet$ & $\bullet$ & $\bullet$ & $\bullet$ & $\bullet$ \\
\hline Sequencing & & & & & & & - & $\bullet$ & $\bullet$ \\
\hline Shipping & & & & $\bullet$ & 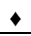 & $\bullet$ & $\bullet$ & $\bullet$ & $\bullet$ \\
\hline \multicolumn{10}{|l|}{ Manufacturing plant } \\
\hline Receiving parts in the input storage & & & $\bullet$ & & & $\bullet$ & & & $\bullet$ \\
\hline Supermarket for assembly & & $\bullet$ & $\bullet$ & & $\bullet$ & $\bullet$ & & $\bullet$ & $\bullet$ \\
\hline JIS storage for assembly & - & $\bullet$ & - & $\bullet$ & - & - & - & - & - \\
\hline Assembly & - & - & - & $\bullet$ & - & - & - & - & - \\
\hline Output storage & $\bullet$ & - & $\bullet$ & - & 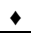 & - & - & 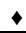 & 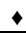 \\
\hline
\end{tabular}

\subsection{Pick-to-sequence supply}

The pick-to-sequence supply is not in any case a just-in-sequence supply for the whole supply chain because the loading unit is sequenced for the customer's demands in the manufacturing plant. The shipping from JIS supplier through intermediate storage to the manufacturing plant can be either just-in-time or just-in-case.

Table 2. Pick-to-sequence strategies to supply manufacturing plants.

\begin{tabular}{|c|c|c|c|c|c|c|c|c|c|c|c|c|}
\hline JIS supplier & 1 & 2 & 3 & 4 & 5 & 6 & 7 & 8 & 9 & 10 & 11 & 12 \\
\hline Outsourced production & $\bullet$ & $\bullet$ & $\bullet$ & $\bullet$ & $\bullet$ & $\bullet$ & 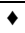 & $\bullet$ & $\bullet$ & 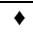 & $\bullet$ & $\bullet$ \\
\hline Storage & $\bullet$ & $\bullet$ & $\bullet$ & $\diamond$ & $\bullet$ & $\bullet$ & $\bullet$ & $\bullet$ & $\diamond$ & $\bullet$ & $\bullet$ & $\diamond$ \\
\hline Building loading units & $\bullet$ & $\bullet$ & $\bullet$ & $\diamond$ & $\bullet$ & $\bullet$ & $\bullet$ & $\bullet$ & $\diamond$ & $\bullet$ & $\bullet$ & $\diamond$ \\
\hline Shipping to intermediate storage & $\bullet$ & $\bullet$ & $\bullet$ & $\bullet$ & $\bullet$ & $\bullet$ & $\bullet$ & $\bullet$ & $\bullet$ & $\bullet$ & $\bullet$ & $\bullet$ \\
\hline Shipping to customer & $\bullet$ & $\bullet$ & $\bullet$ & $\bullet$ & $\bullet$ & $\bullet$ & & & & & & \\
\hline \multicolumn{13}{|l|}{ Intermediate storage } \\
\hline Receiving products from suppliers & & & & & & & $\bullet$ & $\bullet$ & $\bullet$ & $\bullet$ & $\bullet$ & $\bullet$ \\
\hline Storage & & & & & & & $\bullet$ & $\bullet$ & $\bullet$ & $\bullet$ & $\bullet$ & $\bullet$ \\
\hline Building loading units & & & & & & & & & & & & \\
\hline Shipping & & & & & & & $\bullet$ & $\bullet$ & $\bullet$ & $\bullet$ & $\bullet$ & $\bullet$ \\
\hline \multicolumn{13}{|l|}{ Manufacturing plant } \\
\hline Receiving parts in the input storage & $\bullet$ & & $\bullet$ & $\bullet$ & $\bullet$ & $\bullet$ & $\bullet$ & & $\bullet$ & $\bullet$ & $\bullet$ & $\bullet$ \\
\hline Supermarket for production & & & $\bullet$ & & $\bullet$ & & & & $\bullet$ & & $\bullet$ & \\
\hline JIS storage for production & & & $\bullet$ & $\bullet$ & $\bullet$ & $\bullet$ & & & $\bullet$ & $\bullet$ & $\bullet$ & $\bullet$ \\
\hline Production for assembly line & & & $\bullet$ & $\bullet$ & $\bullet$ & $\bullet$ & & & $\bullet$ & $\bullet$ & $\bullet$ & $\bullet$ \\
\hline Output storage for production & & & $\bullet$ & $\bullet$ & $\bullet$ & $\bullet$ & & & $\bullet$ & $\bullet$ & $\bullet$ & $\bullet$ \\
\hline Supermarket for assembly & $\bullet$ & & $\bullet$ & $\bullet$ & & & $\bullet$ & & $\bullet$ & $\bullet$ & & \\
\hline JIS storage for assembly & $\bullet$ & $\bullet$ & $\bullet$ & $\bullet$ & $\bullet$ & $\bullet$ & $\bullet$ & $\bullet$ & $\bullet$ & $\bullet$ & $\bullet$ & $\bullet$ \\
\hline Assembly & $\bullet$ & $\bullet$ & $\bullet$ & $\bullet$ & $\bullet$ & $\bullet$ & $\bullet$ & $\bullet$ & $\bullet$ & $\bullet$ & $\bullet$ & $\bullet$ \\
\hline Output storage & $\bullet$ & $\bullet$ & $\bullet$ & $\diamond$ & $\bullet$ & $\bullet$ & $\bullet$ & $\bullet$ & $\diamond$ & $\bullet$ & $\bullet$ & $\bullet$ \\
\hline
\end{tabular}




\subsection{Build-to-sequence supply}

In the case of build-to-sequence supply of the manufacturing plant, products are produced according to the required sequence of the customer's assembly plant. The just-in-sequence production of required parts can be insourced or outsourced and should be realized based on just-in-time philosophy.

Table 3. Build-to-sequence strategies to supply manufacturing plants.

\begin{tabular}{|c|c|c|c|c|c|c|c|c|}
\hline JIS supplier & 1 & 2 & 3 & 4 & 5 & 6 & 7 & 8 \\
\hline Outsourced production & & & - & 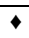 & + & 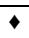 & 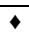 & + \\
\hline Sequencing to customer's needs & & & 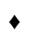 & - & - & & & \\
\hline Storage & & & & & & - & - & - \\
\hline Building loading units & & & & & & - & - & - \\
\hline Shipping & & & - & - & - & - & - & - \\
\hline \multicolumn{9}{|l|}{ Intermediate storage } \\
\hline Receiving products from suppliers & & & & & & 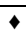 & + & 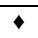 \\
\hline Storage $\mathrm{P}$ (a) & & & & & & - & - & - \\
\hline Sequencing for customer's demands & & & & & & - & - & - \\
\hline Shipping & & & & & & - & - & - \\
\hline \multicolumn{9}{|l|}{ Manufacturing plant } \\
\hline Receiving parts in the input storage & & & 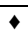 & - & + & 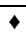 & + & 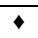 \\
\hline Supermarket for production & & & & & & & & \\
\hline JIS storage for production & & & & & & & & \\
\hline Production for assembly line & - & - & & & & & & \\
\hline Output storage for production & & - & & & & & & \\
\hline Supermarket for assembly & & - & $\bullet$ & - & & - & - & \\
\hline JIS storage for assembly & - & - & - & - & - & - & - & - \\
\hline Assembly & - & - & - & - & - & - & - & - \\
\hline Output storage & - & - & - & - & - & • & • & . \\
\hline
\end{tabular}

The cost function of the analysis of just-in-sequence strategies is based on the costs of production, warehousing, sequencing and transportation.

$$
\begin{aligned}
& C=\min \left(C_{P, \text { out }}, C_{P, \text { in }}\right)+\min \left(C_{W, S u}+C_{W, M a}, C_{W, S u}+C_{W, S t}+C_{W, M a}\right)+ \\
& +\min \left(C_{S e, S u}, C_{S e, S t}, C_{S e, M a}\right)+\min \left(C_{T, S u}+C_{T, M a}, C_{T, S u}+C_{T, S t}+C_{T, M a}\right)
\end{aligned}
$$

The optimization of just-in-sequence strategies can be based on the above mentioned objective function. For production capacities the following constraints have to be taken into consideration (2):

- the outsourced production is less or equal to the production capacity of JIS supplier;

- the internal production is less or equal to the production capacity of manufacturer;

- the sum of outsourced and internal production is equal to the product demand of assembly plant.

$$
q_{P, \text { out }} \leq q_{P, \text { Su }} \text { and } q_{P, \text { in }} \leq q_{P, M a} \text { and } q_{P, \text { out }}+q_{P, \text { in }}=q_{P}
$$

For logistic capacities the following constraints have to be taken into consideration (3):

- the required transportation capacity is less or equal to the available transportation capacities among JIS suppliers, intermediate storages and manufacturers;

- the required warehousing capacities are less or equal to the available capacity in JIS suppliers, intermediate storages and manufacturers.

$$
q_{T, R e q} \leq q_{T, A v} \text { and } q_{W, R e q} \leq q_{W, A v}
$$

The just-in-sequence problems can be solved depending on the complexity of the problems either with LP solution methods or in the case of NP-hard problems with heuristics. 


\section{Summary}

Sourcing strategies are very important for a successful supply chain. It is important to understand how just-in-time based sourcing of manufacturing companies works to choose the best solution. Just-in-sequence solutions support the decrease of inventory levels, but the design and operation of these supply processes can be expensive. Within the frame of this paper authors described a model framework of just-in-sequence supply and defined the most important JIS based supply strategies: ship-to-sequence, pick-to-sequence and build to sequence.

This project has received funding from the European Union's Horizon 2020 research and innovation programme under grant agreement No 691942. This research was partially carried out in the framework of the Center of Excellence of Mechatronics and Logistics at the University of Miskolc.

\section{References}

1. S. Werner, M. Kellner, E. Schenk, G. Weigert, Robot. Comp. Int. Manuf. 19, 107 (2003)

2. A. S. Aradhye, S.P. Kallurkar, Procedia Eng. 97, 2232 (2014)

3. H. Vass, Zs. K. Szabo, Procedia Econ. Fin. 32, 479 (2015)

4. C. O. Brien, M. Head, Int. J. Prod. Econ. 42, 41 (1995)

5. S. K. Goyal, Oper. Res. Quart. 28, 865 (1977)

6. M. Omar, D. K. Smith, Comput. Ind. Eng. 42, 35 (2002)

7. M. Omar, Int. J. Prod. Econ. 118, 185 (2009)

8. A. Banerjee, S. L. Kim, Int. J. Oper. Prod. Manag. 15, 237 (1995)

9. J. L. Cavinato, J. Bus. Log. 13, 285 (1992)

10. T. Y. Choi, J. L. Hartley, J. Oper. Manag. 14, 333 (1996)

11. M. Segura, C. Maroto, Expert. Syst. Appl. 69, 87 (2017)

12. M. Tavana, A. Fallahpour, D. D. Caprio, F. J. Santos-Arteaga, Expert. Syst. Appl. 61, 129 (2016)

13. A. P. Piotrowski, J. J. Napiorkowski, P. M. Rowinski, Inf. Sci. 246, 191 (2014)

14. M. Dorigo, L. M. Gambardella, Biosystems 43, 73 (1997)

15. V. Bhargava, S. E. K. Fateen, A. Bonilla-Petriciolet, Fluid Phase Equilibr. 337, 191 (2013)

16. T. Niknam, S. Sharifinia, R. Azizipanah-Abarghooee, Energ. Convers. and Manage. 76. pp. 1015-1028 (2013)

17. A. R. McKendall, J. Shang, S. Kuppusamy, Comput. Oper. Res. 33, 2431 (2006)

18. S. K. Saha, R. Kar, D. Mandal, S. P. Ghoshal, J. King Saud. Univ. Eng. Sci. 26, 69 (2014)

19. P. R. Srivastava, Comput. Electric. Eng. 43, 270 (2015)

20. P. Veres, T. Bányai, B. Illés, Procedia Eng. 100, 46 (2015)

21. S. M. Wagner, V. Silveira-Camargos, Int. J. Prod. Res. 49, 5713 (2011)

22. J. Kaneko, W. Nojiri, J Transp Geography, 16, 155 (2008)

23. A. N. Dwivedi, Innovative Solutions for Implementing Global Supply Chains in Emerging Markets (Elsevier B.V. 2016)

24. A. Lorenc, M.Szkoda, ICIL 168 (2016)

25. M. Kirch, O. Poenicke, Smart Systech Article number 7156013 (2015)

26. N. Boysen, S. Emde, Eur. J. Oper. Res. 239, 820 (2014)

27. G. Heinecke, S. Lamparter, R. Lepratti, A. Kunz, MIM 1902 (2013) 